\title{
Determining resource intensity weights in ambulatory chemotherapy related to nursing workload
}

by Esther Green, Colin Preyra, Janice Stewart, Cindy McLennan, Rosemary Bland, Tamara Dus, Marcia Langhorn, Kathy Beattie, Annie Cheung, Sherrie Hertz, Haim Sechter, Judy Burns, Helen Angus and Carol Sawka

\begin{abstract}
Ontario cancer programs aim to deliver high-quality nursing care and treatment that is safe for patients and staff. The reality of health care is that financial constraints, inherent in the delivery of care, require that funding mechanisms count not only the cost of drugs, but factors such as pharmacy and nursing human resource costs. While some organizations have developed patient classification systems to measure nursing intensity and workload, these systems apply primarily to inpatient populations, and are fraught with numerous challenges, such as the need for nurses to document to justify the workload required for care. The purpose of this paper is to outline the methodology and engagement of nurses to develop regimen-based resource intensity weights that can be applied to ambulatory chemotherapy suites. The methodology included determination of workload related to nursing time to prepare, teach, counsel and assess patients, as well as time to gather supplies, access lines, monitor, manage adverse reactions, manage symptoms and document care. Resource intensity weights provide better measures of the complexity of care required by cancer patients in ambulatory settings.
\end{abstract}

\section{About the authors \\ Esther Green, RN, BScN, MSc(T), Cancer Care Ontario \\ Colin Preyra, PhD, Institute for Clinical Evaluative Sciences, University of Toronto \\ Janice Stewart, RN, BScN, CON(C), Princess Margaret Hospital, University Health Network}

Cindy McLennan, RN, MBA, CON(C) The Ottawa Hospital Cancer Centre

Rosemary Bland, RN, BSCN, CON(C), CHPCN(C), Juravinski Cancer Centre, Hamilton Health Sciences

Tamara Dus, RN, MN, CONC(C), RS McLaughlin Durham Regional Cancer Centre

Marcia Langhorn, RN, CON(C), London Regional Cancer Centre, London Health Sciences

Kathy Beattie, RN, CON(C), Odette Cancer Centre, Sunnybrook Health Sciences

Annie Cheung, RPh, BScPhm, Cancer Care Ontario

Sherrie Hertz, BScPhm, Cancer Care Ontario

Haim Sechter, MBA Cancer Care Ontario

Judy Burns, BScN, MHSc, CHE, Cancer Care Ontario

Helen Angus, BA(Hons), MScPl, Cancer Care Ontario

Carol Sawka, MD, FRCPC, Cancer Care Ontario

\section{Introduction}

The cancer system in Ontario, Canada, is focused on quality, innovation and performance management. Cancer Care Ontario (CCO) is a data-driven organization; it offers advice to the provincial government based on available evidence and uses best evidence to drive funding decisions, both for treatment as well as capital expenditures.

As a publicly funded cancer system, administrators seek to find methods to accurately measure the costs associated with providing patient care in ambulatory settings. In 1999, CCO's Systemic Therapy Taskforce, consisting of nurses, pharmacists and medical oncologists, examined human resource workload related to systemic treatment. The group used data and available evidence to reach consensus to determine the workload of nurses and pharmacy staff. Tools for methodological analysis were not available at that time, so the group endorsed the use of a rudimentary measure: 1,700 chemotherapy visits per RN FTE, as recommended by the B.C. Cancer Agency (The Systemic Treatment Taskforce, 2000). The measure did not take into consideration the types of chemotherapy regimens, complexity of care, or the nature of the patient population. In 2002, the workload was revised to 1,500 chemotherapy visits per RN FTE (The Systemic Treatment Advisory Working Group [STAWG], 2002) when there was recognition that the initial number was not realistic with changes to new treatment regimen; but again without consideration of the complexity of regimen, or care required by the patient population, such as type of cancer, age, or presence of co-morbidity.

\section{Definition of terms}

Systemic cancer treatment: chemotherapy and supportive care drugs administered via intravenous, intraperitoneal, intrathecal routes.

Resource intensity weights: the average measurement of resources required to deliver systemic treatment services, determined by the actual resources used (such as chair time, nursing and pharmacy resources), linked to the case mix group.

Ambulatory oncology: cancer care provided in an outpatient setting.

Chemotherapy suite: a dedicated setting within an ambulatory unit where nurses deliver systemic treatment.

Human resource needs: staff requirements to deliver cancer care and treatments.

Direct nursing time: point of care nursing time to assess and manage patients.

Indirect nursing time: is the time prepping for and following treatment delivery.

Regimen: a grouping of chemotherapy/supportive care medications that are given together in a set schedule for a specific type of cancer.

Patient education: teaching provided to patients/families about their disease, treatment, potential side effects and symptom management.

Case Mix Index (CMI): A Canadian patient classification system developed by the Canadian Institute for Health Information based upon the most responsible diagnosis used to group patients discharged from acute care hospitals. 
Literature search revealed few tools that were developed to measure the intensity of nursing resource utilization related to systemic cancer treatment. Only one article by Cusack, Jones-Wells and Chisholm (2004), discussed later on in this paper, described the development of a resource intensity tool for oncology. In 2006, the CCO Oncology Nursing Program Committee (ONPC) began a focused dialogue with nursing leaders, managers, staff nurses and advanced practice nurses to consider the development of a tool to define the complexity of care related to chemotherapy regimens used in cancer programs across Ontario. For some time, ONPC members identified that the 1,500 chemotherapy visits per RN (STAWG, 2002) consensus on workload was limited; many managers were concerned that they were unable to describe why fewer patients were being treated by the same number of nursing staff; that is that fewer than 1,500 visits were managed by the nurses. The managers' intuition was that patients required more intensive nursing care during treatment, yet there were no data available to determine complexity or account for the increased nursing time or costs.

In 2007, CCO brought together an expert panel of nursing leaders who were managers and administrators (MSc, MBA, MScN), oncology pharmacists (BPharm), an academic health economist (PhD) and staff nurses (CONC, RNs) knowledgeable about systemic treatment, to develop a methodology to determine resource intensity weights related to 177 unique chemotherapy regimens that included a total of 297 regimens applicable to specific disease sites.

There are a number of terms used in this paper that may not be familiar to all readers. The authors have defined each term for the purpose of clarity (see the Definitions of Terms).

\section{Literature review}

The expert panel first reviewed the literature, searching for advice from nurses who have studied the issues related to nursing workload. A review of the literature revealed interesting variations in tool development and implementation (see Table 1). For example, numerous concepts and tools have been developed to quantify and determine nursing activity to address issues, such as balancing nurse workloads, most often related to inpatient care. Nurse-Patient Assignment Record (Welton, Zone-Smith, \& Bandyopadhyay, 2009), the Ambulatory Intensity System (Cusack, Jones-Wells, \& Chisholm, 2004, Cusack, Jones, \& Chisholm, 2004; Jones, Cusack, \& Chisholm, 2004; Moore \&
Hastings, 2006), Patient Classification Systems (Chabot \& Fox, 2005; Harper \& McCully, 2007), as well as scheduling systems (Langhorn \& Morrison, 2001a; 2001b) are examples of systems of measurement to plan for nursing resources in the ambulatory setting. Some of the tools utilized time and motion studies or relied on objective retrospective quantification of time spent with patients, and some used a combination of the two methods to develop tools (Cusack et al., 2004a, 2004b; Colombo, Solberg, Vanderhoeft, Ramsay, \& Schouten, 2005).

Time and motion studies are intended to measure the allocation of nursing resources in an objective way. While the focus of the tools is on the tasks and the physical elements of care, these tools neglect social or psychological aspects of nursing care, and the assessment, planning, intervention, and evaluation elements of the nursing scope of practice (Harper \& McCully, 2007). Huber and Craig (2007a) recognized that time and motion studies fail to take into account the complex and multidimensional aspects of care mentioned by Harper and McCully (2007). In addition, nursing interventions may be delivered simultaneously, individually or in sequence (Huber \& Craig, 2007b). The variety of interventions that a nurse selects, and the variation of how these are timed to be delivered, also contribute to the complexity of measuring care. Time and motion studies attempt to measure what actually occurs, as opposed to what would occur under a reference standard of care. Moreover, they are expensive and time-consuming to develop, and the work-sampling methods may be subject to the Hawthorne effect, where the subjects change their work habits due to being observed (Colombo et al., 2005). Finally, scheduling or determining nursing costs was usually the premises on which some of these tools were designed.

The concept of defined "intensity" categories, or levels of care, related to the amount of time required to administer each regimen, and the notion of levels of acuity (Chabot \& Fox, 2005; Langhorn \& Morrison, 2001a; 2001b) are essential elements that need to be considered in relevant tools. Unruh (2008) recognized that there is a need for an evidence-based, standardized measure of workload that can assess all effects of known contributing factors, including direct and indirect nursing time (Morris, MacNeela, Scott, Treacy, \& Hyde, 2007). While a variety of tools have been developed to measure patient acuity and/or intensity of nursing care, each tool has advantages and disadvantages. There is little in the way of literature available to support nursing resource allocations at a micro-level (e.g.,

Table 1. Summary of tools for nurse resource intensity

\begin{tabular}{|l|l|l|l|}
\hline Author \& Year & Tool & Type & Purpose \\
\hline Chabot \& Fox (2005) & $\begin{array}{l}\text { Patient Classification } \\
\text { System }\end{array}$ & Nursing consensus & $\begin{array}{l}\text { Workload measurement in chemotherapy } \\
\text { scheduling }\end{array}$ \\
\hline Harper \& McCully (2007) & $\begin{array}{l}\text { Patient Classification } \\
\text { System and Acuity } \\
\text { tools }\end{array}$ & $\begin{array}{l}\text { Time and motion studies or a patient care } \\
\text { checklist with assigned acuity scores/ } \\
\text { ratings }\end{array}$ & $\begin{array}{l}\text { To predict staffing needs and more } \\
\text { accurately control nurse-to-patient ratios }\end{array}$ \\
\hline $\begin{array}{l}\text { Colombo, Solberg, } \\
\text { Schouten (2005). }\end{array}$ & $\begin{array}{l}\text { Tool name not } \\
\text { provided }\end{array}$ & $\begin{array}{l}\text { Combination Time and Motion Study and } \\
\text { Retrospective Study }\end{array}$ & $\begin{array}{l}\text { Planning nurse staffing levels and } \\
\text { assessing workload in hematology- } \\
\text { oncology wards }\end{array}$ \\
\hline $\begin{array}{l}\text { Cusack, Jones-Wells, } \\
\text { \& Chisholm (2004); } \\
\text { Chisack, Jones, \& } \\
\text { \& Hastings (2006) }\end{array}$ & $\begin{array}{l}\text { Ambulatory Intensity } \\
\text { System }\end{array}$ & Nurse-reported retrospective study & $\begin{array}{l}\text { Planning nurse staffing levels and } \\
\text { assessing workload in ambulatory } \\
\text { chemotherapy, medical/surgical, pediatric } \\
\text { and hematology/oncology day hospital } \\
\text { settings }\end{array}$ \\
\hline $\begin{array}{l}\text { Langhorn \& Morrison } \\
\text { (2001a, 2001b) }\end{array}$ & $\begin{array}{l}\text { Chemotherapy } \\
\text { Scheduling System }\end{array}$ & $\begin{array}{l}\text { Opis Complexity Weighted Units } \\
\text { standardized nursing intensity/procedure } \\
\text { in minutes) and the Alberta Cancer Board's } \\
\text { "Nursing Workload System" }\end{array}$ & $\begin{array}{l}\text { Workload measurement in chemotherapy } \\
\text { scheduling }\end{array}$ \\
\hline $\begin{array}{l}\text { Welton, Zone-Smith, \& } \\
\text { Bandyopadhyay (2009) }\end{array}$ & $\begin{array}{l}\text { Nurse-Patient } \\
\text { Assignment Record }\end{array}$ & $\begin{array}{l}\text { Nurse-reported retrospective study \& the } \\
\text { Nursing Intensity Database }\end{array}$ & $\begin{array}{l}\text { Calculating nursing intensity and direct } \\
\text { nursing costs }\end{array}$ \\
\hline
\end{tabular}


an ambulatory chemotherapy clinic) and even less to support decision-making at a macro-level (e.g., provincial or regional level). In ambulatory systemic cancer settings, patient resource requirements are highly associated with patient treatment regimen, yet available classifications did not recognize this variation. The purpose of this paper is to outline the development of regimen-based resource intensity weights applicable to ambulatory chemotherapy suites.

\section{Methodology}

\section{The panel}

An expert panel was formed including an academic health economist (PhD), pharmacists (BPharm) with oncology expertise, nursing leaders (MSc, MScN, $\mathrm{CON}(\mathrm{C})$ ), oncology nurses $(\mathrm{RN}, \mathrm{CON}(\mathrm{C})$ ), and managers (MBA) experienced in cancer systemic treatment. The goals of this initiative were two-fold: 1) to determine the nursing care required to manage patients receiving complex chemotherapy regimens, including multiple drug regimens, for all cancer disease sites, including the elements of direct and indirect care, and 2) to assign a weighting that would be used to fund systemic treatment in Ontario cancer centres. The expert panel was selected because of their expertise and ability to work collaboratively through dialogue working toward consensus. Rather than employing time and motion methodology, and given the collective knowledge of the panel on chemotherapy regimen implementation in practice, the panel used a consensus-based approach on each of the nursing care dimensions. Nurses on the panel were representatives of large academic and medium-sized community cancer programs. The nurses' experience working in oncology ranged between 10 and 20 years. The economist and other members of the panel had relevant experience in their respective fields, ranging between five and 10 years.

\section{The process}

The panel was constituted with discipline-specific expertise, direct care experience, financial management and knowledge of cancer drugs used to treat different cancer types. This mix of expertise and knowledge benefited the discussion and debate on each workload item, definition and allocation. The consensus-based approach was chosen for several important reasons:

- Focus could be placed on best practice workload allocation, as opposed to current practice;

- Cost of the study was significantly reduced through the use of consensus;

- Comparisons with current hospital workload systems, which themselves were calibrated using time and motion studies, evidenced a high degree of concordance with the results of this study;

- The consensus process allowed consideration of all regimens;

- The templates and consensus-based framework developed through this process, are readily updated as new regimens appear in practice (review of the weights is done each year, as new regimens are added).

- Finally, the consensus methodology does not require nursing staff to enter any data, thus relieving additional workload from direct care providers.

\begin{tabular}{|c|c|c|c|}
\hline \multirow{2}{*}{$\begin{array}{l}\text { Column } \\
\text { A: }\end{array}$} & \multirow{2}{*}{\begin{tabular}{|l|} 
Workload item \\
VAD access/IV start and \\
disconnect \\
20 minutes for each type \\
of access (i.e. IV, IP) \\
\end{tabular}} & \multicolumn{2}{|l|}{ Definitions of each element of regimen workload } \\
\hline & & $\begin{array}{l}\text { - Accessing central lines, flushing and } \\
\text { assessment of patency of VAD } \\
\text { - Blood draw from VAD if required } \\
\text { - Dressing change of central line }\end{array}$ & $\begin{array}{l}\text { - Peripheral IV access and assessment } \\
\text { - Disconnect and flushing of VAD/IV } \\
\text { - Does not apply to G-tube or intravesicular access }\end{array}$ \\
\hline B: & $\begin{array}{l}\text { Prep Time } \\
15 \text { minutes }\end{array}$ & $\begin{array}{l}\text { - Review of chemotherapy orders, blood work, } \\
\text { allergies, current nursing assessment if seen } \\
\text { in clinic or reviewing self-assessment record } \\
\text { if direct-to-chemo } \\
\text { - Review of last treatment } \\
\text { - NPAT (new patient): review of history } \\
\text { and consultation report }\end{array}$ & $\begin{array}{l}\text { - Review of protocol and administration guidelines } \\
\text { - Identifying and gathering of necessary equipment } \\
\text { - Preparing flush lines } \\
\text { - Gowning of PPE } \\
\text { - Ensuring consent was signed }\end{array}$ \\
\hline C: & $\begin{array}{l}\text { Education } \\
15 \text { minutes }\end{array}$ & $\begin{array}{l}\text { - NPAT (new patient): chemo education } \\
\text { - Ongoing reinforcement of chemo education w }\end{array}$ & ith each patient visit \\
\hline D: & $\begin{array}{l}\text { Documentation } \\
15 \text { minutes }\end{array}$ & $\begin{array}{l}\text { - Documentation (paper or electronic chart) of: } \\
\text { - IV/VAD access } \\
\text { - drugs administered } \\
\text { - symptom presentation and toxicities } \\
\text { - interventions required }\end{array}$ & $\begin{array}{l}\text { - Documentation (paper or electronic chart) of: } \\
\text { - response to treatment } \\
\text { - chemo teaching } \\
\text { - status on discharge } \\
\text { - telephone calls with MDs, allied health, CCAC }\end{array}$ \\
\hline $\mathrm{E}:$ & $\begin{array}{l}\text { Toxicity Assessment and } \\
\text { Symptom Management } \\
15 \text { minutes }\end{array}$ & $\begin{array}{l}\text { - Assessment of patient if direct-to-chemo } \\
\text { - Symptom management (use medical } \\
\text { directives if appropriate) }\end{array}$ & $\begin{array}{l}\text { - NCIC Grading where needed } \\
\text { - Interventions (i.e., calling physician, blood draws, } \\
\text { possible admissions) }\end{array}$ \\
\hline F: & $\begin{array}{l}\text { Antiemetics, } \\
\text { Pre-medications or } \\
\text { Additional Medications } \\
5 \text { minutes for } \\
\text { simple antiemetic } \\
\text { premedications ( } \leq 2 \text { meds) } \\
7 \text { minutes for more } \\
\text { complex antiemetic } \\
\text { premedications ( } 3 \text { or } \\
\text { more meds) }\end{array}$ & $\begin{array}{l}\text { - Administration of antiemetics as ordered } \\
\text { - Obtaining order if patient forgot to save } \\
\text { antiemetic or to take prior to treatment } \\
\text { - Administering premedications via G-tube }\end{array}$ & $\begin{array}{l}\text { - Require order if symptom presentation new } \\
\text { or not controlled } \\
\text { - Administration of diuretic } \\
\text { - Getting oral fluids for patient to take pills }\end{array}$ \\
\hline
\end{tabular}


Early in the process, the lead nurse (EG) contacted several health care institutions to gather information about their use of workload measures in chemotherapy suites in Canada. Most of the institutions contacted used modified inpatient classification systems or acuity tools, but did not employ any methods for capturing workload in chemotherapy beyond the number of patients treated, the volume of regimen used and the number of nurses working in chemotherapy suites.

The first phase of work began with identifying all the activities associated with nursing workload. Definitions for each activity were agreed upon and documented to support the subsequent phases. The objective was to ensure comprehensiveness and to establish a baseline that would then incorporate variation on a regimen-by-regimen basis. At the outset of work, several exclusion criteria were agreed upon: clinical trial regimens, oral drugs, and in-patient regimens. Clinical trial regimens were excluded because these drugs were not funded or approved for funding and, therefore, did not apply. Oral medications were excluded because these required limited nursing time. In-patient regimens were excluded because these represented a minority of treatments delivered.
The second phase of work was completed by each nursing team member independently. Each panel member made a determination of the required time per regimen visit from his/her own experience. The group then reviewed any discrepancies in time allocations and reached consensus for each regimen; the number became the final time allocation for each required activity. Although, in some instances, originally reported nursing times did vary by hospital, the panel worked to ensure that the reported times reflected a standard of care. The remaining nursing activities were understood to vary by regimen. All regimens currently being used and those regimens anticipated to be increasingly prevalent were added subsequently, which brought the total number of regimens reviewed to 177 . This number (177) reflected the total number of unique regimens.

\section{Workload items}

Table 2 outlines each workload item and the time required for each item. These items include: venous access, intravenous start and disconnect; prep time; patient education, and so on. The next step for the panel was to discuss, consider and agree on the time for each workload item. For example, documentation requires 15 minutes;

\begin{tabular}{|c|c|c|c|}
\hline Column & Workload item & \multicolumn{2}{|l|}{ Definitions of each element of regimen workload } \\
\hline G: & $\begin{array}{l}\text { Regimen nursing time } \\
\text { delivery }\end{array}$ & \multicolumn{2}{|c|}{ 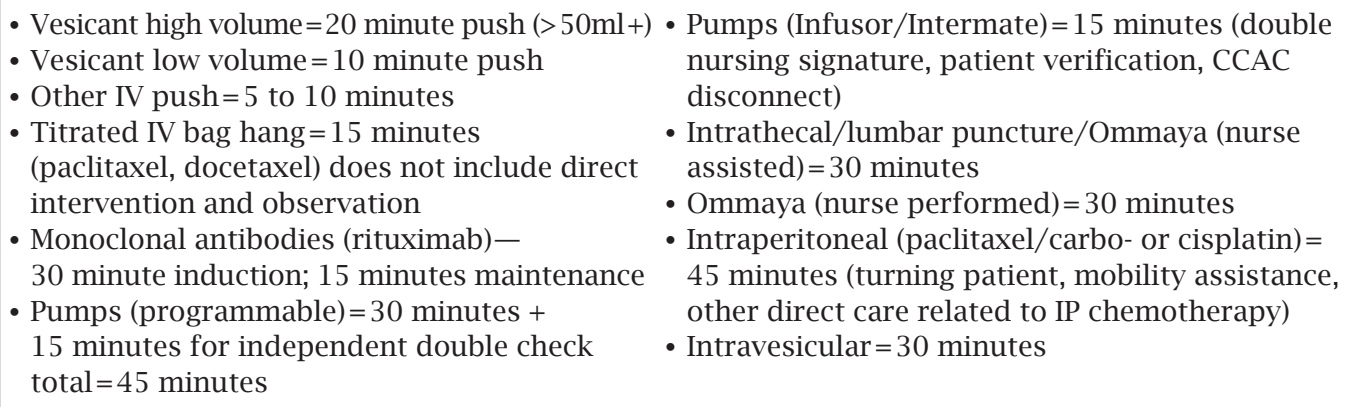 } \\
\hline H: & Hydration & $\begin{array}{l}\text { - Pre and post hydration with cisplatin= } \\
5 \text { minutes }\end{array}$ & $\begin{array}{l}\text { - } \mathrm{Ca} / \mathrm{Mg} \text { infusions pre- and post-oxaliplatin= }=5 \text { minutes } \\
\text { - Other hydration }=5 \text { minutes }\end{array}$ \\
\hline I: & $\begin{array}{l}\text { Observation Post- } \\
\text { Treatment }\end{array}$ & $\begin{array}{l}\text { - } 1 \text { hour observation period =10 minutes } \\
\text { nursing workload time }\end{array}$ & $\begin{array}{l}\text { - } 30 \text { minutes observation period }=5 \text { minutes } \\
\text { nursing workload time }\end{array}$ \\
\hline $\begin{array}{l}\text { J.i. \& } \\
\text { J.ii.: }\end{array}$ & $\begin{array}{l}\text { Average Reaction } \\
\text { High Probability }=7.5 \\
\text { minutes } \\
\text { Medium Probability }=2.5 \\
\text { minutes } \\
\text { Low Probability }=0.75 \\
\text { minutes }\end{array}$ & $\begin{array}{l}\text { - Calling physician } \\
\text { - Vital signs, interventions related to vital signs } \\
\text { - Administration of medications } \\
\text { - Second nurse involved } \\
\text { - Average reaction: } \\
\text { - High probability: 20-30 minutes nursing } \\
\text { time required for reaction: asparaginase IV, } \\
\text { carboplatin, oxaliplatin, paclitaxel, docetaxel, } \\
\text { rituximab } \\
\text { - Medium probability: 10-15 minutes nursing } \\
\text { time required for reaction: pegylated } \\
\left.\text { liposomal doxorubicin (Caelyx }{ }^{\circledR}\right) \\
\text { interferon-alfa-2b, paclitaxel weekly, etoposide, } \\
\text { cetuximab, trastuzumab, temsirolimus } \\
\text { - Low probability: 5-10 minutes nursing time } \\
\text { required for reaction: bleomycin, asparaginase }\end{array}$ & $\begin{array}{l}\text { - Probability of reaction: } \\
\text { - High: } 30 \% \\
\text { - Medium: } 20 \% \\
\text { - Low: } 10 \% \\
\text { - Average reaction time per cycle = probability } \times \\
\text { average reaction time } \\
\text { - High: } 7.5 \text { minutes }=0.3 \times 25 \text { minutes } \\
\text { - Medium: } 2.5 \text { minutes }=0.2 \times 12.5 \text { minutes } \\
\text { - Low: } 0.75 \text { minutes }=0.1 \times 7.5 \text { minutes }\end{array}$ \\
\hline $\mathrm{K}:$ & $\begin{array}{l}\text { Bring in and turnaround } \\
5 \text { minutes }\end{array}$ & $\begin{array}{l}\text { - Paging/calling patient into room } \\
\text { - Accompanying patient to designated } \\
\text { chair/bed and assisting as required }\end{array}$ & $\begin{array}{l}\text { - Patient verification/identification } \\
\text { - Patient comfort items } \\
\text { - Disposal of all equipment used in cytotoxic delivery }\end{array}$ \\
\hline \multirow[t]{2}{*}{ L: } & $\begin{array}{l}\text { Infection control practices } \\
5 \text { minutes }\end{array}$ & \multicolumn{2}{|l|}{$\begin{array}{l}\text { - Isolation } \\
\text { - Arranging for staff to clean chair or bed }\end{array}$} \\
\hline & Total fixed time & \multicolumn{2}{|l|}{ Columns A + B $+C+D+E+F+K+L$} \\
\hline \multirow[t]{2}{*}{ M: } & $\begin{array}{l}\text { Multitask adjuster of } 33 \\
\text { of fixed total }\end{array}$ & \multicolumn{2}{|l|}{$($ Columns A + B + C + D + E + F+ K+L)*1/3 } \\
\hline & Nurse intensity time & \multicolumn{2}{|l|}{ Columns $\mathrm{G}+\mathrm{H}+\mathrm{I}+\mathrm{J}+\mathrm{M}$} \\
\hline
\end{tabular}


however, the number of pre-medications required in each regimen will vary depending on how many medications are included: less than two requires five minutes; three or more requires more time. Amount of intravenous hydration required for safe patient care was dependent on the regimen. For example, hydration needs for the drug Cisplatin was five minutes; whereas other drugs require no pre- or posthydration for the patient. Reaction time was another area requiring both the expertise of the panel members and knowledge of the type of drug. For example, some regimens will result in high probability of reaction, requiring more nursing assessment and management. For high probability, the time assigned to the regimen was 20 to 30 minutes; for low probability, time was five to 10 minutes of nursing time. The panel spent considerable time on each of the definitions and time requirements, revisiting the decisions based on each regimen.

\section{Workload intensity}

The time for regimen workload assessed included many elements, such as vascular access, start and disconnect peripheral or central line access; preparation time to review the orders, blood work; patient education; documentation; toxicity assessment and symptom management; and additional medications required and so on. Table 2 identifies all the workload items and times including direct patient care and indirect elements from accessing lines through to time allocation for infection control practices (columns A to L). Specific areas were assigned a variable depending on the number of pre-meds required $(\mathrm{F})$; nursing time required for administration of specific drugs such as monoclonal antibodies (G); observation time required (I); and probability of reactions $(\mathrm{J})$. It should also be noted that the literature was reviewed for these specific dimensions, to ensure that the best available evidence was incorporated into the time dimensions. For example, the variation of high, medium and low probability of reaction was identified for specific drugs based on evidence from the literature and clinical practice. The panel also identified the need for additional time to administer regimens that were delivered either by intra-peritoneal or intravesicular routes. Since this work involved measurement of nursing time, the panel recognized that multitasking by nurses needed to be accounted for. To incorporate this notion of multitasking, total fixed time was first determined by adding the time factors for each of the columns: A, B, C, D, E, F, K and L.

\section{The review process}

Detailed review of the workload processes and comparison of the single task time counts with multitask time counts suggested that $33 \%$ was an appropriate additional factor. Accordingly, fixed time was multiplied by $33 \%$ to account for nurse engagement in multiple tasks (common factors) and multiple patients, as they work in chemotherapy suites. The final calculation to determine Nursing Intensity Time was realized by adding time factors in columns $\mathrm{G}$, $\mathrm{H}, \mathrm{I}, \mathrm{J}$ and $\mathrm{M}$, the multitask adjustment. These factors (G, H, I, J)

\begin{tabular}{|c|c|c|c|c|c|c|c|c|c|c|c|c|c|c|c|c|c|}
\hline Regimen code & Regimen description & A & B & $\mathrm{C}$ & D & $\mathbf{E}$ & $\mathbf{F}$ & G & $\mathbf{H}$ & I & J.i. & J.ii. & K & $\mathbf{L}$ & $\begin{array}{l}\text { Total } \\
\text { fixed } \\
\text { time }\end{array}$ & M & $\begin{array}{c}\text { Nurse } \\
\text { intensity } \\
\text { time }\end{array}$ \\
\hline DOCETAX-100 & $\begin{array}{l}\text { BREAST, GASTROINTESTINAL, } \\
\text { GENITOURINARY - DOCETAXEL } \\
\text { Q21 DAYS }\end{array}$ & 20 & 15 & 15 & 15 & 15 & 5 & 15 & 0 & 0 & High & 7.5 & 5 & 5 & 95 & 31.7 & 54 \\
\hline $\begin{array}{l}\text { FOLFIRI- } \\
\text { BEVACIZUMAB }\end{array}$ & $\begin{array}{l}\text { GASTROINTESTINAL - } \\
\text { COLORECTAL, IRINOTECAN, } \\
\text { FLUOROURACIL CIV, } \\
\text { LEUCOVORIN, BEVACIZUMAB }\end{array}$ & 20 & 15 & 15 & 15 & 15 & 5 & 35 & 0 & 0 & 0 & 0 & 5 & 5 & 95 & 31.7 & 67 \\
\hline GEM-CISP & $\begin{array}{l}\text { GENITOURINARY - BLADDER OR } \\
\text { LUNG OR HEAD AND NECK OR } \\
\text { BREAST OR HEMATOLOGY OR } \\
\text { GASTROINTESTINAL-BILIARY, } \\
\text { GEMCITABINE, CISPLATIN }\end{array}$ & 20 & 15 & 15 & 15 & 15 & 5 & 10 & 5 & 0 & 0 & 0 & 5 & 5 & 95 & 31.7 & 47 \\
\hline CHOP & $\begin{array}{l}\text { HEMATOLOGY -NON- } \\
\text { HODGKIN'S LYMPHOMA } \\
\text { - CYCLOPHOSPHAMIDE, } \\
\text { DOXORUBICIN, VINCRISTINE, } \\
\text { PREDNISONE }\end{array}$ & 20 & 15 & 15 & 15 & 15 & 5 & 35 & 0 & 0 & 0 & 0 & 5 & 5 & 95 & 31.7 & 67 \\
\hline $\begin{array}{l}\text { FLUD-CYCLO- } \\
\text { RITUXIMAB }\end{array}$ & $\begin{array}{l}\text { HEMATOLOGY - FLUDARABINE, } \\
\text { CYCLOPHOSPHAMIDE, } \\
\text { RITUXIMAB (AKA FCR) }\end{array}$ & 20 & 15 & 15 & 15 & 15 & 5 & 20 & 0 & 5 & High & 7.5 & 5 & 5 & 95 & 31.7 & 64 \\
\hline PACLICISP-IP & $\begin{array}{l}\text { GYNECOLOGICAL - PACLITAXEL, } \\
\text { IP CISPLATIN }\end{array}$ & 40 & 15 & 15 & 15 & 15 & 7 & 45 & 5 & 10 & High & 7.5 & 5 & 5 & 117 & 39.0 & 107 \\
\hline BCG & $\begin{array}{l}\text { GENITOURINARY - BCG } \\
\text { (INTRAVESICULAR) }\end{array}$ & 0 & 15 & 15 & 15 & 15 & 5 & 30 & 0 & 0 & 0 & 0 & 5 & 5 & 75 & 25.0 & 55 \\
\hline $\begin{array}{l}\text { AC-TAXOL- } \\
\text { TRASTUZ }\end{array}$ & $\begin{array}{l}\text { BREAST - DOXORUBICIN, } \\
\text { CYCLOPHOSPHAMIDE (AC), THEN } \\
\text { PACLITAXEL, TRASTUZUMAB }\end{array}$ & 20 & 15 & 15 & 15 & 15 & 7 & 25 & 0 & 5 & High & 7.5 & 5 & 5 & 97 & 32.3 & 70 \\
\hline
\end{tabular}


represent regimen variation, such as reaction, delivery time, hydration and observation. While these calculations may seem onerous, by using this method of adding time factors for each of these elements and the multitask adjustment, the final nurse intensity time was identified for each regimen. Nurses are not required to do the calculations; the time factor for each regimen has been completed and is available on the CCO formulary for each regimen.

An example of eight regimens is shown in Table 3 to demonstrate how the time factors differ by regimen. For example, the nurse workload related to a protocol using intraperitoneal chemotherapy requires more observation time, has a higher probability of reaction (PACLICISP-IP), and is greater than the protocol to deliver GEM-CISP.

\section{Discussion}

\section{Implications for the system}

The required nursing resources per case vary by diagnosis and treatment plan. A facility treating relatively more resource intensive regimens will have a case mix index higher than the provincial average (see Figure 1). As well, facilities may decide to use a different regimen for a specific diagnosis, which may vary in the number of expected visits in comparison to the actual visits (see Figure 2). In the CCO Activity Level Reporting database (which is a key component of the Ontario

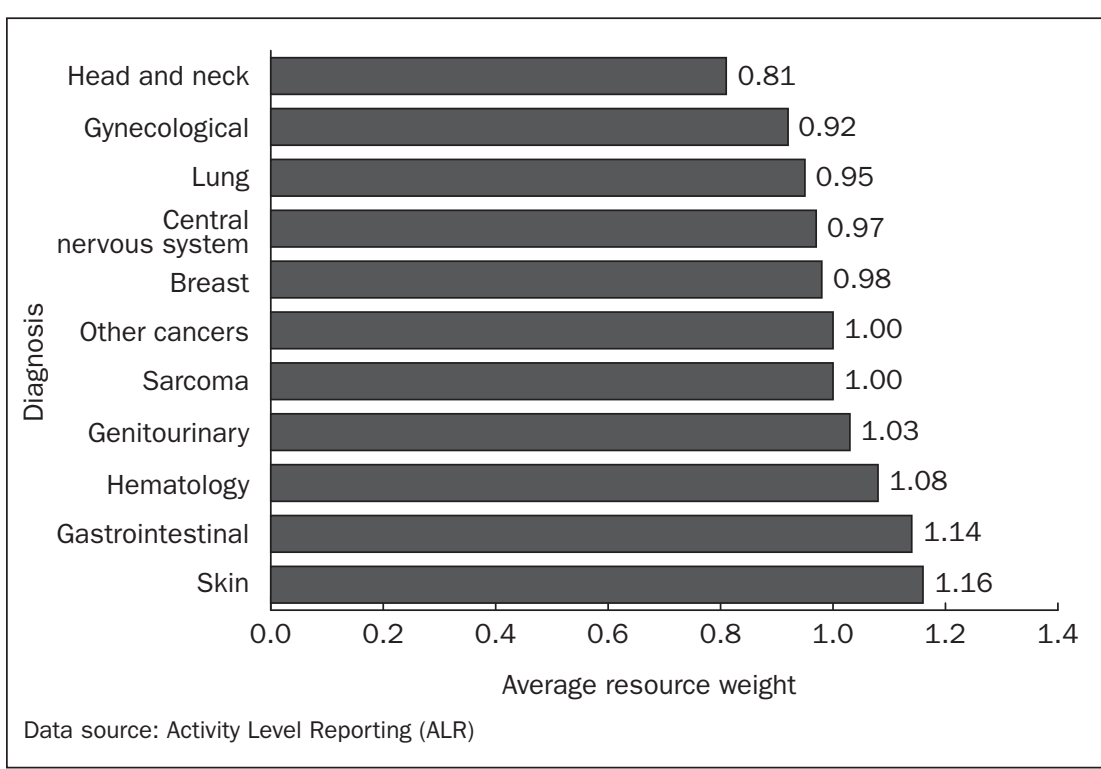

Figure 1. Average resource weight by diagnosis, 2009-10

\begin{tabular}{|c|c|c|c|c|c|c|}
\hline \multicolumn{3}{|c|}{ Facility $A$} & \multirow{2}{*}{$\begin{array}{r}\begin{array}{c}\text { Actual } \\
\text { visits }\end{array} \\
15\end{array}$} & \multirow{2}{*}{$\begin{array}{r}\begin{array}{c}\text { a } \\
\text { Expected } \\
\text { visits }\end{array} \\
10\end{array}$} & \multirow{2}{*}{$\begin{array}{r}\begin{array}{c}\text { b } \\
\text { Resource } \\
\text { weight per visit }\end{array} \\
0.13\end{array}$} & \multirow{2}{*}{ 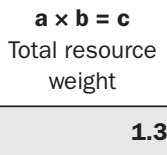 } \\
\hline Patient 1 & Regimen 5 & Diagnosis A & & & & \\
\hline Patient 2 & Regimen 1 & Diagnosis B & 2 & 3 & 0.3 & 0.9 \\
\hline Facility case mix & & & \multicolumn{4}{|c|}{$(1.3+0.9) \div 2=1.10$} \\
\hline Funding rate per case & & & \multicolumn{4}{|c|}{$\$ 3,300 \times 1.1=\$ 3,630$} \\
\hline
\end{tabular}

\begin{tabular}{|c|c|c|c|c|c|c|}
\hline \multicolumn{3}{|c|}{ Facility B } & Actual & $\begin{array}{c}\mathbf{a} \\
\text { Expected }\end{array}$ & $\begin{array}{c}\text { b } \\
\text { Resource }\end{array}$ & $\begin{array}{c}\mathbf{a} \times \mathbf{b}=\mathbf{c} \\
\text { Total resource }\end{array}$ \\
\hline Patient 1 & Regimen 10 & Diagnosis A & 17 & 20 & 0.11 & 2.2 \\
\hline Patient 2 & Regimen 1 & Diagnosis B & 2 & 3 & 0.3 & 0.9 \\
\hline Facility case mix & & & & & $(2.2$ & $0.9) \div 2=1.55$ \\
\hline Funding rate per case & & & & & $\$ 3,300$ & $1.55=\$ 5,115$ \\
\hline
\end{tabular}

Figure 2.
Cancer Registry), there are 177 unique regimens that are delivered in cancer programs across the province. Regimens are applied to disease sites and the variation occurs according to the dosing and use of the regimen related to a specific disease site. This means that some regimens require more or fewer visits depending on patient-specific factors. The number of visits and number of cases per disease site were reviewed, as part of the overall determination of case mix.

The work of the expert panel served as an aid to distribute the pool of funds for systemic treatment in a way that better reflects resource intensity. The goal of this project was to develop an equitable funding model that would reflect the actual regimens being delivered and would ensure alignment of funding with quality goals. Funding allocation is currently based on the number of new consultations seen by medical oncologists, which provides a base funding amount. Moreover, annual incremental funding is required to pay for the growth in the number of new cases added to the caseload. Resource intensity weighting provides a methodology to coordinate funding and planning of systemic treatment delivery to promote the efficient use of resources at the local level. Regimen data that include utilization of systemic treatment are reported consistently in the cancer programs and can now be used to customize incremental funding to the actual resources required to deliver care. CCO assumed an average cost of 1.0 and plotted all regimens relative to that cost. This means that a regimen with a weighting of 1.2 costs $20 \%$ more than the provincial average cost. All regimens delivered by a program are used to calculate the unique case mix index (CMI). In order to further validate the CMI, the panel looked at the results over three years and found that for all cancer programs the case mix was stable. CCO has committed to an annual update of each program CMI, based on the actual regimens delivered.

This resource intensity weight tool has allowed the cancer system in Ontario to build an objective platform on which to negotiate funding with the Ministry of Health and Long-Term Care that reflects the state of systemic treatment today. The tool and methodology has been reviewed by all the cancer programs in Ontario. In addition, a number of the programs used the information to aid in the development of nursing scheduling within ambulatory chemotherapy suites.

\section{Implications for nursing}

A benefit of this work was the thorough knowledge and understanding gained regarding nursing workload issues. The final nurse intensity time (refer to Table 2) demonstrates that regimens require different times for patient care; this confirmed the intuition that managers had when a regimen changed or a new regimen was introduced, that the amount of available nursing time needed to be adjusted. It should be noted that the key to the success of this project was the motivation on the part of the funder and stakeholders to ensure the development of an equitable, clinically meaningful funding formula that would facilitate the ongoing integration of planning, standards and funding. Since the model was intended to support funding, it received an intense degree of scrutiny from the perspective of users, resulting in a comprehensive, robust case mix system.

Reviews on a regimen-by-regimen basis also resulted in important discussions related to variation in practice by program. Variation in regimen use among similar patient groups indicated that efficiency improvements were 
generally possible in the system by substituting low for high resource intensive regimes. Furthermore, diversity of regimens in use by disease site indicated that increased standardization in the province was possible.

The resource allocation model was developed by combining: a) population-based demand for services at the regional level based on incidence and utilization, and b) patient and provider adjusted methodology for costing/funding. The previous funding system was limited in its ability to: reflect the complexity of systemic treatment and care related to regimens, adapt as new regimens became available and support the sustainability of community oncology clinics. A recently published study conducted in six chemotherapy centres in New South Wales, Australia, identified the factors of patient education, patient assessment, administration and patient communication as core components to determining nurse workload (De Raad et al., 2010). The work by these authors acknowledges and confirms that direct care requires more than the administration of the drugs.

The work to define Resource Intensity Weights for complex regimen enable nurses and managers to identify high workload intense protocols and care requirements, and provides the opportunity to plan staffing levels to meet the needs of cancer patients. As a result of this work, there is a synchronized funding model for the systemic treatment modalities of cancer nursing care. The potential use of a dynamic funding model is important in times of financial constraints to fund appropriate care requirements and leverage improvements in quality.

\section{Implications for patients}

The development of the Resource Intensity Weights has an indirect implication for patients in that the allocation on nursing resources is now based on a methodology. There is now a more consistent

\section{REFERENCES}

Chabot, G., \& Fox, M. (2005). The creation of a patient-classification system in an outpatient infusion center setting. Oncology Nursing Forum, 32(3), 535-538.

Colombo, A., Solberg, B., Vanderhoeft, E., Ramsay, G., \& Schouten, H. (2005). Measurement of nursing care time of specific interventions on a hematology-oncology unit related to diagnostic categories. Cancer Nursing, 28(6), 476-480.

Craig, K., \& Huber, D. (2007). Acuity and case management: A healthy dose of outcomes (Part II). Professional Case Management, 12(4), 199-210.

Cusack, G., Jones-Wells, A., \& Chisholm, L. (2004). Patient intensity in an ambulatory oncology research center: A step forward for the field of ambulatory care (Part I). Nursing Economics, 22(2), 58-63.

Cusack, G., Jones, A., \& Chisholm, L. (2004). Patient intensity in an ambulatory oncology research center: A step forward for the field of ambulatory care (Part III). Nursing Economics, 22(4), 193195.

De Raad, J., van Gool, K., Haas, M., Haywood, P., Faedo, M., Gallego, G., Pearson, S., \& Ward, R. (2010) Nursing takes time: Workload associated with administering cancer protocols. Clinical Journal of Oncology Nursing, 14(6), 735-741.

Harper, K., \& McCully, C. (2007). Acuity systems dialogue and patient classification system essentials. Nursing Administration Quarterly, 31(4), 284-299.

Huber, D., \& Craig, K. (2007a). Acuity and case management: A healthy dose of outcomes (Part I). Professional Case Management, 12(3), 132-44.

Huber, D., \& Craig, K. (2007b). Acuity and case management: A healthy dose of outcomes (Part III). Professional Case Management, 12(5), 254-69. approach to providing nursing care that is inclusive of both direct and indirect elements. Managers can assign nurses to meet the complex needs of patients receiving all chemotherapy regimens.

\section{Limitations of the tool}

The tool was reviewed by a number of groups (Oncology Nursing Provincial Committee, Regional Systemic Treatment Program, Provincial Leadership Council) in Ontario. However, a fulsome external review beyond Ontario was not conducted. The ability of the tool to generalize to cancer programs outside of the Ontario context will need to be determined by other jurisdictions, in consideration of the application to unique regimens.

\section{Conclusions}

In complex cancer environments, it is essential that the need for nursing resources is related to the needs of the patients receiving care and treatment. The work of this group was intended to develop regimen-based resource intensity weights methodology that would include all elements of direct care and indirect care. The method allows nurses and managers to identify high-intensity regimens and the nursing care requirements to support staffing changes, as well as provides data to justify case costing.

\section{Acknowledgements}

The authors would like to gratefully acknowledge the contributions to this article from the following people: Linda Robb-Blenderman (Kingston General Hospital), Tracy McQueen (Kingston General Hospital), Mychele Sabourin (The Ottawa Hospital Regional Cancer Program), Leila Shenouda (Princess Margaret Hospital), Jayesh Patel (Princess Margaret Hospital), Johnathan Lam (CCO), Julia Gao (CCO) and Naomi Greenberg (CCO).

Jones, A., Cusack, G., \& Chisholm, L. (2004). Patient intensity in an ambulatory oncology research center: A step forward for the field of ambulatory care (Part II). Nursing Economics, 22(3), 120123.

Langhorn, M., \& Morrison, C. (2001a). Redesigning processes in ambulatory chemotherapy: Creating a patient appointment scheduling system (Part I). Canadian Oncology Nursing Journal, 11(2), 109-110.

Langhorn, M., \& Morrison, C. (2001b). Redesigning processes in ambulatory chemotherapy: Creating a patient appointment scheduling system (Part II). Canadian Oncology Nursing Journal, 11(3), 157-159.

Moore, M., \& Hastings, C. (2006). The evolution of an ambulatory nursing intensity system-Measuring nursing workload in a day hospital setting. Journal of Nursing Administration, 36(5), 241248.

Morris, R., MacNeela, P., Scott, A., Treacy, P., \& Hyde, A. (2007). Reconsidering the conceptualization of nursing workload: Literature review. Journal of Advanced Nursing, 57(5), 463-471.

The Systemic Therapy Advisory Working Group [STAWG] (2002). Report of the systemic therapy advisory working group, Ontario (unpublished report). Presented to the Ministry of Health and Long Term Care and Cancer Care Ontario.

The Systemic Therapy Task Force. (2000). Systemic therapy task force report. Ontario: Presented to Cancer Care Ontario (unpublished report). April 2000.

Unruh, L. (2008). Nurse staffing and patient nurse and financial outcomes. The American Journal of Nursing, 108(1), 62-71.

Welton, J.M., Zone-Smith, L., \& Bandyopadhyay, D. (2009). Estimating nursing intensity and direct cost using the nurse-patient assignment. Journal of Nursing Administration, 39(6), 276-284. 